\title{
Introduction: Philosophy of Sex and Gender in Gender Medicine
}

\author{
M. Cristina Amoretti ${ }^{1} \cdot$ Nicla Vassallo $^{1}$
}

Published online: 23 August 2017

(C) Springer Science+Business Media B.V. 2017

\section{Gender Medicine and its Philosophical Relevance}

In the last few decades, the relevance of the two variables of sex and gender in influencing health and diseases, not only those clearly sex- and gender-related, has been increasingly acknowledged. Sex and gender differences, it has been recognised, are not confined to genital organs and reproductive functions, but pertain to almost all bodily systems, and cover the entire life cycle of the human being, from the antenatal period and birth, through childhood, adolescence, and adulthood, to old age and death. Moreover, the sex of single cells can make a difference from a medical point of view. Given this understanding, a new field of medicine or, maybe, a new perspective on medicine-that is, gender medicine or gender-specific medicine-recently emerged and has rapidly advanced.

Broadly speaking, gender medicine investigates when and how sex and gender differences matter in medicine by examining their deep relationships with human physiology, pathophysiology, clinical features, and the course of diseases. According to Marianne J. Legato-a cardiologist by training, as well as one of the pioneers and most active promoters of gender medicine-this new field of medicine, or this new way to look at medicine, can be seen as

the study of how the normal function and the experience of disease differ between men and women. It is as dedicated to the study of the unique aspects of men's biology as it is to that of women; indeed, it is the com-

M. Cristina Amoretti

cristina.amoretti@unige.it

1 DAFIST, Philosophy Section, University of Genoa, Via Balbi 4, 16126 Genoa, Italy parison between the two sexes that has prompted some of the most interesting and novel questions in medicine (Legato 2010, p. xxi).

At least three points are worth emphasising. To begin, even if it's true that the origin of gender medicine is, at least in part, related to the women's health movement, this medical field should not be thought of as femaleor women-specific medicine, as it aims at investigating the relationships of both sexes and genders with medical research and clinical practices. Moreover, despite the fact that only two sexes and genders are typically mentioned in the relevant literature, gender medicine is not committed to considering sex and gender as dichotomous variables (see, e.g., Fausto-Sterling 1985). Finally, though there may be some ambiguities with regard to the distinction between sex and gender, these two notions must be kept separated, as they affect medical research and clinical practice differently. The former refers solely to biological and physiological differentiations, whereas the latter also takes into account cultural, historical, psychological, and social influences, roles, values, and expectations (see, e.g., Mikkola 2016). From a medical point of view, however, these two variables intersect and deeply affect each other: on the

\footnotetext{
1 While the first centre for gender-specific medicine was founded in 2001 in New York, there are now many of them all over the world, as well as important scientific journals (such as, The Journal of Gender Specific Medicine, then supplanted by Gender Medicine) and societies (such as, The International Society of Gender Medicine) dedicated to this approach. Books assembling the most relevant results in virtually all fields of medicine are also numerous; see for instance, Legato (2002), Legato and Bilezikian (2010), Oertelt-Prigione and Regitz-Zagrosek (2012), and Schenck-Gustafsson et al. (2012). Recent theoretical reflections on gender medicine can also be found in Gadebusch-Bondio and Katsari (2014).
} 
one hand, sex-related factors-e.g., different expressions of genes in $\mathrm{X}$ and $\mathrm{Y}$ chromosomes, hormones, or muscle mass-may have an effect on gendered behaviours and roles; on the other hand, gender-related elements-e.g., different exposure to stress and environmental toxins, poor nutrition, or training - may lead to sex-related genetic and epigenetic modifications.

That sex and gender influence all aspects of medicine can hardly be questioned. They can be seen to influence the incidence, diagnosis, treatment, and prognosis of diseases, as well as their risk factors, clinical manifestations, pathophysiological course, the effects of pharmacological interventions, the patient's personal experience of disease, the identification of one's health care needs, the access to health care facilities, the doctor-patient exchanges and relationship, and more. If the impact of sex and gender in medicine is so wide and profound, why has it been ignored, or at least underestimated, for so long? The reasons are numerous, of course, but it is crucial to mention the pervasive presence of biases and stereotypes against women, biases and stereotypes that are extremely difficult to eradicate.

In particular, women have long been considered as "small men", whose relevant biological and physiological differences were limited to genital organs and reproductive functions. This prejudice brought with it at least two deleterious consequences. On the one hand, until recently, the majority of diseases affecting both sexes had exclusively been studied in male patients, and females had been excluded from medical trials, so that findings in the male population became the standard for all populations, including female patients (see, e.g., Dresser 1992; Raz and Miller 2012; Rogers 2004). Excluding female patients from medical research was obviously a moral mistake, but also an epistemic one, as it created serious gaps and blind spots in medical knowledge and clinical practice (the literature on cardiovascular diseases affecting female patients is a pioneering example of such gaps and blind spots-see, e.g., Shaw and Redberg 2004). On the other hand, the cultural, long-lasting stereotype that being a woman is essentially related to being a reproducer, a child bearer, or a mother had been reinforced and somehow justified by medicine. This contributed to perpetrating old, and producing new, gaps and blind spots in medical knowledge, as well as deep health care inequalities that are still hard to overcome (see, e.g., Regitz-Zagrosek and Seeland 2012; Rogers 2004). Considering sex and gender as relevant medical variables, gender medicine providentially exposed these important issues. It not only introduced new medical questions, hypotheses, theories, and research that couldn't have been even conceived of before, thus furthering our medical knowledge and practice, but it also helped to uncover sex and gender biases and stereotypes that obstructed medical progress and generated deep inequalities in health care.
Emphasising the relevance of the variables of sex and gender in influencing health and diseases, gender medicine similarly contributed to creating a novel, fascinating, and still largely unexplored framework for philosophical reflection (see, e.g., Gergel 2017). From a philosophical point of view, many crucial issues - that, of course, may be more or less directly related to gender medicine - are, in fact, worthy of consideration. To take some examples: Which notions of sex and gender may be more appropriate to gender-medicine and medicine in general? Is the distinction between sex and gender still tenable or useful in medicine? Is sex and gender dualism a viable option for medicine? How is the appreciation of sex and gender differences able to fill knowledge gaps and blind spots with respect to both medical diagnostics and treatments? Might increasing the number of women among medical communities ensure better, more objective, more rational, unbiased, or, at least, "less false" medical hypotheses and theories? Might sex- or gender-related values influence how clinical evidence is acquired and interpreted? Do they influence the way in which some key medical concepts are defined? Do similar values obstruct or favour the growth of medical knowledge? What is the role of sex and gender biases and stereotypes in shaping the doctor-patient relationship? Is there any relevant sex and gender difference in the phenomenology of illness? The eight contributions to this special issue, which are briefly summarised below, are relevant and original examples of how gender medicine has inspired new, stimulating, and wide-ranging philosophical discussions.

\section{The Contributions to this Issue}

Among other things, we have mentioned that sex and gender can have a direct impact on access to health care. In the paper Sex in medicine: What stands in the way of credibility?, Mari Mikkola examines a specific case study of this type, that is, childfree females who encounter greater obstacles than childfree males in obtaining voluntary sterilisation. She considers whether such a disparity can be explained by evoking Miranda Fricker's notion of testimonial injustice (Fricker 2007), according to which individuals belonging to disadvantaged groups (in this case, female patients) are taken to be less credible than those belonging to advantaged groups (male patients). Mikkola interestingly notes that the case of voluntary sterilisation points to a subtly different way in which female patients can suffer testimonial injustice: childfree females encounter credibility deficits pertaining not to their immediate and current beliefs and desires, but to their future, still dormant, but truly authentic beliefs and desires-future beliefs and desires that, following the cultural stereotype that being a female/woman essentially means being a mother, would include fulfilling the 
childbearing function. Ignoring childfree females' current request for sterilisation because of gendered assumptions and implicit biases about their future beliefs, Mikkola concludes, clearly undermines their ability to grant informed consent.

Although gender biases can make it more difficult for female than for male patients to obtain voluntary sterilisation, most other commercial contraception methods directly target female users. As Emmalon Davis points out in her What is it to share contraceptive responsibility?, while access to contraception is not always considered a woman's right, controlling reproduction is almost always considered her own responsibility. That the majority of contraception methods are directed to the female body, in fact, unfairly burdens women, who become disproportionately vulnerable to related financial, physical, and emotional hardships. According to Davis, the development of female-controlled contraception methods certainly enhanced female sexual health and reproductive freedom, but it also influenced cultural attitudes towards contraception, making women the primary bearers of contraceptive responsibility. This "feminisation of contraception" disadvantages women in several ways. For instance, they bear most of the costs and risks associated with contraception, and become the main target of moral contempt when "irresponsible" procreative choices are at issue. Davis then claims that men should start sharing the burdens of contraception more equitably; this would be possible by making new contraceptive technologies for men readily available and, more importantly, changing cultural attitudes towards contraceptive responsibility.

The problem of implicit biases, which can not only lead to credibility and autonomy deficits in the doctor-patient exchange, but also to systematic errors of reasoning, is further analysed by James A. Marcum in his Clinical decision-making, gender bias, virtue epistemology, and quality healthcare. He focuses on gender bias in clinical reasoning and decision-making, a kind of bias that reflects either gender blindness or stereotype, and has a negative impact, especially on women's health, leading to over- or underdiagnosis, misdiagnosis, and wrong or bad treatments. Marcum's main point is that the negative impact of gender bias can be corrected or even prevented by embracing some key tenets of virtue epistemology (see, e.g., Turri and Alfano 2017). Even if both reliabilist and responsibilist versions of virtue epistemology can be used to this end, he limits his analysis to the latter. He thus considers the role of some relevant intellectual virtues (e.g., traditional virtues, such as nous, phronesis, techne, and episteme, as well as contemporary virtues, such as intellectual humility, honesty, justice, and courage) with regard to cardiovascular and coronary hearth diseases, where women have long been discriminated against. Marcum then concludes that virtue epistemology can successfully assist gender medicine by replacing gender bias with gender awareness and sensitivity, eliminating the associated errors of reasoning, and, thus, improving the quality of health care.

While Mikkola and Marcum address different aspects of the doctor-patient relationship by focusing on the medical practitioners' side, Eileen Willis, Debra King, Jo Wainer, and Kei Owada examine the patient's point of view. In their Women and gynaecological cancer: Gender and the doctor-patient relationship, they try to shed light on the gendered nature of care that women with gynaecological cancer receive from healthcare professionals. Their research shows that, even if women generally declare to prefer female gynaecologists, those with gynaecological cancer develop a positive therapeutic relationship with their male gynaecological oncologists/surgeons, which is not extended to their female nurses. Willis and her colleagues explain these findings by appealing to the division of labour in health care, power and status differences between doctors and nurses, and the way in which the oncologist/surgeon's higher status is helpful to the patient. In the case of gynaecological cancer, which has deep implications for the patient's sexual and reproductive functions, the oncologist/surgeon's higher status contributes to creating a de-eroticised, positive, and therapeutic doctor-patient relationship. This relationship is improved when the oncologist/surgeon is a male, as, for heterosexual women, having a man that recognises them as women throughout the various stages of cancer can help them to recombine their gendered and sexual identities.

We have seen that gender medicine has contributed to exposing sex and gender biases that negatively influenced medical knowledge and clinical practice. Arguing for the elimination of these biases can be read as a way of promoting a more value-free medicine, that is, a medicine freer from non-epistemic values (such as cultural, economic, moral, or religious values). However, as Anke Bueter argues in Androcentrism, feminism, and pluralism in medicine, gender medicine should not be seen as an example of a more value-free science, but rather of a better value-laden science. Bueter supports her reading by analysing the origins of gender-medicine, rooted in the feminist women's health movement, as well as one of its milestones, the inclusion of women in clinical trials. From these examples, she concludes that gender medicine contributed to the progress of medicine by introducing new relevant value-laden perspectives on health and diseases. Such an introduction does not threaten objectivity, as long as objectivity is conceived in Helen Longino's terms, as social objectivity, a procedural notion that refers to the process of knowledge production, which should be a process of pluralistic and democratic mutual criticism (Longino 1990). This process does not aim at a value-free science, but it is nonetheless our best way to detect value-laden assumptions, implicit biases, and blind spots, and thus to enhance the progress of medicine. 
Gender biases and stereotypes, and non-epistemic values in general, can not only hide or trump the empirical evidence, but also influence the way in which the empirical evidence is interpreted and used to set clinical guidelines. In her Place of birth: Ethics and evidence, Leah McClimans discusses a clinical case where the same empirical evidence has been evaluated in opposite ways because of different non-epistemic values. The case study she focuses on regards the professional and moral opportunity to encourage non-obstetric births. To begin, she points out that the same empirical evidence, that is, data coming from the same study, is used to support both obstetric and non-obstetric births, because this empirical evidence is interpreted in light of different non-epistemic values. To solve the disagreement, some scholars propose to evaluate the non-epistemic values at issue; however, McClimans suggests taking a more finegrained look at the empirical evidence. She distinguishes between questions of risk acceptability, which involve nonepistemic values and subjective interests, and questions of safety, which are more objective, as they concern the relative risk of non-obstetric birth compared to obstetric birth, and then proposes to focus on the latter. This move can delineate a framework where the influence of non-epistemic values is minimised and the actual need to seek out further empirical evidence is made explicit.

Contemporary medicine still has a dichotomous conception of sex and gender: one individual can be either a female/ woman or a male/man, while "ambiguous" cases must be "normalised" to fit one of the two sexes or genders (see, e.g., Dreger 1998). In her Intersex diagnostics and prognostics: Imposing sex-predicate determinacy, Stephanie Julia Kapusta claims that, from a semantic point of view, sex predicates are linearly and multi-dimensionally vague, as well as indeterminate. As vagueness and indeterminacy are not acceptable from a medical and social point of view, Kapusta examines the medical procedures of sex assignments for intersex infants, which aim at imposing determinate sex predicates. She individuates two stages. First, "standard" measures of genital morphology are preliminarily used to conceal vagueness by stipulating clear, but largely arbitrary, boundaries between the extensions of the sex predicates "female" and "male", and the extension of the sex predicate "intersexed", including all borderline cases. Second, some dimensions of biometrical data are prioritised to avoid indeterminacy and assign to borderline cases a sex of rearing, a therapeutic and pedagogical project aiming at producing determinate, stable, and socially recognised sex and gender identity. In the author's view, the final goal of this two-stage procedure is to render the indeterminacy of sex predicates as socially invisible.

The problem of intersex people is extremely relevant for medicine and philosophy of medicine, as it is not clear whether or not they should be considered "diseased" just because of their intersex condition (Amoretti and Vassallo 2015). Of course, many other medical conditions are worthy of philosophical consideration-ageing, deafness, and infertility being some major examples. In her contribution, The regulation of gender in menopause theory, Sylvie Gambaudo focuses on menopause and examines the most relevant theories that have been proposed to explain it, from the early accounts to the contemporary ones. Among the latter, the most relevant ones cast menopause at the outcome of evolution and/or as a medical condition. Her main point is that evolutionary and medical accounts of the menopausal experience support a strong relationship between menopause and regulation, as they see reproduction as the main regulatory force in the understanding of what constitutes a woman. In this way, Gambaudo claims, menopause acquires a negative connotation, as it represents an anomalous area of experience that no longer conforms to what is socially recognised as a woman. The menopause experience, however, can be also framed in contrast to these established theories and then used to resist the dominant ideology of gender. In this way, it can become a new area for identity politics and the site of dissident narratives.

Acknowledgements We are extremely grateful to all contributors, without whom this topos would not have been possible. We also thank the many referees who collaborated with us and contributed to putting together this collection, as well as the editorial assistants at Springer for taking prompt action whenever it was needed. Last but not least, we are also extremely grateful to Fabio Paglieri, editor in chief of Topoi, for having accepted our proposal. We hope the final result might be to his satisfaction.

\section{References}

Amoretti MC, Vassallo N (2015) Against sex and gender dualism in gender-specific medicine. In: Mäki U, Votsis I, Ruphy S, Schurz G (eds) Recent developments in the philosophy of science: EPSA13 Helsinki. Springer, Dordrecht, pp 357-368

Dreger AD (1998) Hermaphrodites and the medical invention of sex. Harvard University Press, Cambridge

Dresser R (1992) Wanted-single, white male for medical-research. Hastings Cent Rep 22:24-29

Fausto-Sterling A (1985) Myths of gender. Biological theories about women and men. Basic Books, New York

Fricker M (2007) Epistemic injustice: power and the ethics of knowing. Oxford University Press, Oxford

Gadebusch-Bondio M, Katsari E (eds) (2014) "Gender-Medizin": Krankheit Und Geschlecht in Zeiten Der Individualisierten Medizin. De Gruyter, Bielefeld

Gergel TL (2017) Gender medicine and phenomenological embodiment. In: Marcum JA (ed) The Bloomsbury companion to contemporary philosophy of medicine. Bloomsbury, London, pp 227-248

Legato MJ (2002) Eve's rib: the new science of gender-specific medicine and how it can save your life. Harmony Books, New York

Legato MJ (2010) Preface. In: Legato MJ, Bilezikian JP (eds) Principles of gender-specific medicine. Elsevier, Amsterdam, pp xxi-xxii 
Legato MJ, Bilezikian JP (eds) (2010) Principles of gender-specific medicine, 2nd edn. Elsevier, Amsterdam

Longino H (1990) Science as social knowledge: values and objectivity in scientific inquiry. Princeton University Press, Princeton

Mikkola M (2016) Feminist perspectives on sex and gender. In: Zalta EN (ed), The Stanford encyclopedia of philosophy. http://plato. stanford.edu/entries/feminism-gender/. Accessed 08 Aug 2017

Oertelt-Prigione S, Regitz-Zagrosek V (eds) (2012) Sex and gender aspects in clinical medicine. Springer, London

Raz L, Miller VM (2012) Considerations of sex and gender differences in preclinical and clinical trials. In: Handbook of experimental pharmacology. Springer, Berlin, pp 127-147

Regitz-Zagrosek V, Seeland U (2012) Sex and gender differences in clinical medicine. In: Handbook of experimental pharmacology. Springer, Berlin, pp 3-22
Rogers W (2004) Evidence-based medicine and women: do the principles and practice of EBM further women's health? Bioethics 18:50-71

Schenck-Gustafsson K, DeCola PR, Pfaff DW, Pisetsky DS (eds) (2012) Handbook of clinical gender medicine. Karger, Basel

Shaw LJ, Redberg RF (2004) Contemporary cardiology: coronary disease in women: evidence-based diagnosis and treatment. Humana Press, Totowa

Turri J, Alfano M (2017) Virtue epistemology. In Zalta EN (ed) The Stanford encyclopedia of philosophy. https://plato.stanford.edu/ entries/epistemology-virtue/. Accessed 08 Aug 2017 